\title{
Mundos perdidos, paraísos perdidos: ciudad primitiva y utopía imposible en Los que no descienden de Eva (1941), de Luis Antonio de Vega
}

\author{
Mariano MARTÍn RODRÍGUEZ \\ Centrul de Cercetări Literare şi Enciclopedice \\ Universitatea "Babeş-Bolyai", Cluj-Napoca (Rumanía) \\ martioa@yahoo.com
}

Recibido: 07/09/2012

Modificado: $12 / 12 / 2013$

Aceptado: $25 / 02 / 2013$

\section{Resumen}

A mediados del siglo XX, la crisis de la Modernidad propició un cambio de paradigma en la ficción de mundos perdidos. A diferencia de las fantasías imperialistas anteriores que acababan incorporando simbólicamente la raza perdida a la civilización occidental supuestamente superior, varias novelas de mundos perdidos modernas pintan sociedades primitivas que presentan los rasgos de la perfección utópica y encarnan el sueño cumplido del paraíso. Por desgracia, el ser humano contemporáneo no siempre parece digno de disfrutar la primitiva ciudad deseada. Por ejemplo, en la arqueoficción Los que no descienden de Eva (1941), de Luis Antonio de Vega, el hombre es intrínsecamente imperfecto e incapaz de regresar al paraíso perdido. Este ejemplo brillante español de la ficción de mundos perdidos explota hábilmente la noción pesimista de una utopía esencialmente imposible.

Palabras clave: mundos perdidos, utopía, paraíso, Luis Antonio de Vega.

Title: Lost Worlds, Lost Paradises: Primitive City and Impossible Utopia in Those Who Are Not Descended from Eve (1941), by Luis Antonio de Vega

\section{Abstract}

The crisis of Modernity in mid-twentieth century led to a paradigm shift in lost world fiction. Unlike former imperialist fantasies in which the lost race was symbolically incorporated into the allegedly superior Western civilization, several modernist lost world romances depict primitive societies endowed with utopian perfection, embodying thus the accomplished dream of paradise. Unfortunately, contemporary mankind does not always seem worthy of enjoying the primitive desired city. For example, in the lost race tale Those Who Are Not Descended from Eve (1941), by Luis Antonio de Vega, man is inherently flawed and unable to return to the lost paradise. This brilliant Spanish example of lost world fiction skilfully exploits the pessimistic notion of an essentially impossible utopia.

Keywords: lost worlds, utopia, paradise, Luis Antonio de Vega.

\section{Índice}

1. Mundos perdidos y (anti)utopía

2. Los pasos perdidos de Luis Antonio de Vega: Los que no descienden de Eva y el paraíso imposible 


\section{Mundos perdidos y (anti)utopía}

La mutación de mentalidades propiciada por la Revolución Industrial favoreció, entre otras cosas, un enriquecimiento de la literatura centrada en pintar sociedades radicalmente distintas a las del mundo real. A la utopía, o descripción de la ciudad perfecta, y al viaje imaginario, o narración de aventuras en espacios que reflejan como espejos deformadores las aberraciones y ridículos de la civitas mundana, se sumaron nuevos géneros temáticos ajustados a las nuevas circunstancias. Por ejemplo, la creciente influencia del progreso científico y técnico facilitó una boga también creciente de la ciencia ficción como género capaz de dotar de nueva plausibilidad al sueño o la pesadilla de la ciudad por venir. Otro género de enorme fortuna popular respondió a las nuevas exigencias de verosimilitud en la creación de un universo especulativo, pero situaba la ciudad imaginaria no en un futuro fantaseado, sino en el pasado, un pasado milagrosamente pervivido para disfrute del aventurero $y$, subsidiariamente, de los lectores. De esta forma, se perseguía a la vez el atractivo de la ambientación histórica y el de la explotación literaria del deseo utópico. Este género es lo que se suele denominar en inglés lost-race fiction o lost world romance y que en español podríamos llamar arqueoficción, dadas sus raíces en los progresos de la Arqueología. Esta modalidad literaria (antes de pasar al cine y a la historieta) experimentó un gran auge en la segunda mitad del siglo XIX y la primera mitad del siglo XX. Las exploraciones marítimas habían vuelto increíbles las islas fabulosas habituales en los viajes imaginarios, pero cabía aún la posibilidad de pensar que existieran en los diversos parajes continentales todavía no hollados por el hombre blanco no solo poblaciones exóticas desconocidas, sino también comunidades que hubieran prolongado hasta la época contemporánea civilizaciones antiguas, cuya desaparición propiciaba una especie de nostalgia culturalista que tiene su correlato en la moda paralela de la novela arqueológica (histórica). Se podía concebir incluso que hubiera también lugares tan aislados que hubiesen podido conservar la flora y fauna extinguidas que los progresos de la Paleontología estaban dando a conocer, al mismo tiempo que los arqueólogos aventureros sacaban a la luz ruinas espléndidas, cuya noticia la prensa difundía enseguida entre las masas. Todos estos avances, muy publicitados, facilitaron que se aceptara la plausibilidad de la existencia de razas y mundos perdidos $y$, por ende, su aprovechamiento literario. Según afirma Guillaud (1993: 13) refiriéndose a este tipo de narraciones:

La majorité des ouvrages [...] concerne des voyages "réels", rendus crédibles par les possibilités illimitées des sciences nouvelles et des conquêtes coloniales. La fiction est soudainement concurrencée par la réalité. Les découvertes de Troie, de Zimbabwe, de Machu Picchu, du tombeau de Toutankhamon, tout cela fait de l'époque l'âge d'or de 
l'archéologie et de l'exploration scientifique, avec lesquelles la fiction est en relation naturelle.

Tales descubrimientos conferían a estas arqueoficciones una verosimilitud de nuevo cuño, acorde también con la mayor exigencia de realismo en la literatura coetánea en general. Si a ello se añade su estrecha relación con la empresa colonial, sin la cual era difícil pensar siquiera en descubrir razas perdidas a falta de la exploración sistemática que constituía el requisito previo a la ocupación de cualquier territorio, no extrañará demasiado su fortuna en los decenios de expansión imperialista, ni que el género fuera cultivado sobre todo en Francia y, más aún, en las dos grandes potencias anglosajonas: "Especially in both Britain and America, during those years between the 1870 s and the 1930 s, by far the most popular kind of imaginary voyage took the form of the so-called 'lost-race' novel" (Clareson 1985: 118). Bastará recordar a este respecto el éxito ininterrumpido de novelas como King Solomon's Mines ${ }^{1}(1885)$ y She (1887), de H. Rider Haggard, o de The Lost World (1912), de Arthur Conan Doyle ${ }^{2}$, a las que se pueden sumar las reediciones de las arqueoficciones populares de Edgar Rice Burroughs (por ejemplo, The Land That Time Forgot, 1918, de título significativo), entre otras muchas menos recordadas hoy. En lengua francesa, además de los relatos de J.-H. Rosny aîné en los que este maestro de la ficción prehistórica imagina la supervivencia de una fauna antediluviana y de distintas especies de homínidos ("Nymphée", 1893; "Les Profondeurs de Kyamo", 1896, etc.), se pueden recordar el superventas, muy bien escrito por lo demás, de Pierre Benoît L'Atlantide ${ }^{3}$ (1919), que consagró el mito, ya presente en She, de la princesa letalmente atractiva, y varias arqueoficciones casi olvidadas, pero que se tradujeron contemporáneamente al español, entre las que cuentan, por ejemplo, L'Épouse du soleil/ ${ }^{4}$ (1915), de Gaston Leroux; La Cité des premiers hommes ${ }^{5}$ (1929), de Maurice Champagne, ambas sobre todo de aventuras, y otra quizá menos convencional, la fictocientífica Le Peuple du pôle ${ }^{6}$ (1907), de Charles Derennes, a las que se puede

\footnotetext{
${ }^{1}$ Las minas de Salomón, traducción de Gaziel, Barcelona, Seix Barral, 1921. Solo indicamos las traducciones anteriores a la arqueoficción de Vega considerada. Existen muchas otras versiones españolas posteriores.

${ }^{2}$ El mundo perdido, traducción de F. R. Vadillo, Madrid, Marisal, 1940.

${ }^{3}$ Esta novela celebérrima, que inspiró luego una magistral versión cinematográfica de Georg Wilhelm Pabst filmada en 1932 en tres versiones lingüísticas distintas (Die Herrin von Atlantis, L'Atlantide, The Mistress of Atlantis), fue traducida al español por Rafael Cansinos-Asséns (La Atlántida, Madrid, G. Hernández y Salo Sáez, 1927).

${ }^{4}$ La esposa del Sol, traducción anónima, Madrid, Saturnino Calleja, 1917.

${ }^{5}$ La ciudad de los primeros hombres, traducción anónima publicada en la colección periódica La Novela Fantástica en 1932.

${ }^{6}$ El pueblo del polo, traducción de Manuel Abril, Madrid, Jimenez y Molina, 1921.
} 
sumar la castamente erótica Sirenide ${ }^{7}$ (1921) italiana de Nino Salvaneschi. Estas obras no eran todas necesariamente procoloniales. Por ejemplo, el erotismo de la Ayesha de Haggard o de la Antinéa de Benoît pone de relieve más bien la vulnerabilidad del aventurero europeo, que queda atrapado tanto como el lector por la fascinación refinada y bárbara a la vez de esas figuras femeninas, además de servir de comentario sobre la actualidad $^{8}$. No obstante, la arqueoficción solía narrar sobre todo el triunfo del hombre blanco sobre la sociedad descubierta, por mucho que esta se presentara con todo el prestigio de la antigüedad. Se trataba de fantasías de posesión que respondían a una actualización del impulso utópico de acuerdo con la nueva cosmovisión económica y política del capitalismo triunfante, según han señalado varios estudiosos. Para Rieder, "[t]he plots of 'romantic' lost-race fiction can be summarized on the whole as fantasies of appropriation in (and sometimes of) the 'virgin territory' of previously inaccessible foreign lands" (2008: 40).

Estas fantasías tenían, en efecto, un carácter marcadamente utópico, aunque de forma un tanto paradójica. No se trataba de contar el ascenso del self-made man en el marco empírico de la novela realista, sino de dar una imagen fantástica de ese ascenso, en forma de quimera utópica de sustitución. En palabras de Khouri, "[i]n a dream of conquest coupled with a desire to recapture a utopianized lost history, the witness-traveller looks backward to reconsider a utopian past divorced from historical becoming" (1983: 171). Sin embargo, la función del visitante quedaba invertida, pues el viajero admirador ya no deseaba integrarse en la ciudad utópica, sino reconfigurar la ciudad utópica a la medida de sus deseos: "The lostrace utopist does not seek any democratic equality with the dominated classes; he yearns to be in the place of the dominant class" (188). Se trataba de apoderarse de los tesoros y de la mano de la princesa, esto es, de satisfacer los anhelos más profundos del varón (post)victoriano. Con esto se afirmaba, al paso, la superioridad de la sociedad occidental contemporánea sobre la decadente y aislada del espacio utópico, que quedaba así anulada. Incluso físicamente, pues suele ocurrir en estas ficciones que la intervención del explorador ponga en marcha una mecánica que acaba terminando enteramente con la civilización descubierta, sea por aculturación, sea

${ }^{7}$ El reino de las sirenas, traducción de R. M. Tenreiro, Madrid, Reus, 1928.

8 En Benoît, "I'Antiquité historique, mythique, biblique renaît dans un décor contemporain, en sorte que le souvenir des événements les plus anciens vient éclairer l'actualité, projetant sur elle une lumière poétique et symbolique" (Foucrier 1994: 27). Vega haría exactamente lo mismo en Los que no descienden de Eva, que guarda bastantes similitudes con la célebre arqueoficción del autor francés. Según Carrasco González, "[h]ay unas claras similitudes con La Atlántida de Pierre Benoit en su planteamiento pero difiere en el humor y la resolución" (2009: 229). 
a causa de una catástrofe natural o política. El mundo perdido podía ser un paraíso, pero sus habitantes y su sociedad milagrosamente supervivientes se equiparaban a efectos prácticos con los salvajes que, en la imaginación colonial, distaban de merecer tal edén (Street 1975: 127):

[T] he knowledge of European man's place at the top of the evolutionary tree and his inherited superiority over these earlier forms of life forces the author to place in this paradise a race of men as savage and bloodthirsty as the traveller's tales had led people to expect. These lowly creatures have failed to take full advantage of their environment; so they require the benevolent trusteeship of their superior white brothers to put them on the right path.

Este molde de la arqueoficción fue el más común y tiene ejemplos hasta en literaturas, como la española, sin demasiada tradición en la ficción de aventuras exóticas, aventuras que solían servir de excipiente narrativo a la descripción del mundo perdido y de su raza o razas. Sin embargo, una modalidad tan popular no podía quedar sin émulos y el principal escritor español de novela popular en el período de entreguerras (mundiales), Jesús de Aragón, publicó en 1929 la arqueoficción más fiel a los modelos imperialistas anglosajones, La ciudad sepultada, la cual presenta convencionalmente casi todos los cronotopos del género, ya convertidos en lugares comunes. No obstante, la arqueoficción tuvo en España otras manifestaciones de mayor pretensión literaria que reflejaron, además, su mutación desde sus inicios proimperialistas. De hecho, si la arqueoficción popular había prolongado durante un largo período el convencimiento colonial de la superioridad blanca y occidental moderna, no faltaron obras de la modalidad escritas por intelectuales más atentos al signo de los tiempos, a la crisis de valores subsiguiente a la Gran Guerra. En ese momento de conciencia de crisis, la utopía de los mundos perdidos se transformó a veces en su contrario. En arqueoficciones distópicas como Land under England, de Joseph O'Neill, o La Révolte des volcans, de Camille Audigier, publicadas ambas el mismo año y de asunto parecido, "le héros est lui-même tenté d'abdiquer sa personnalité, anticipation symbolique du processus d'apathie collective que frappera les peuples subissant le joug totalitaire" (Guillaud 2000: 111). Estas dos novelas son parábolas transparentes del nazismo, aunque el hecho de presentar ambas como raza perdida a los descendientes robotizados de legiones romanas supervivientes en espacios subterráneos ilustra también, en forma de parábola, que el imperialismo totalitario del presente no hacía sino heredar usos antiguos. La narrativa de mundos perdidos se convirtió así en una especie de distopía de un pasado sometido a juicio mediante la ficción, tal como sugieren también las dos 
principales arqueoficciones distópicas españolas en este registro, el relato "En la caverna encantada" (1929 en la Argentina; luego recogido en El libro de las narraciones, 1936), de José María Salaverría, y El Dorado (1942), de Ricardo Baroja. En ambas, aventureros modernos acceden a unas comunidades aisladas en Sudamérica que son trasuntos de las legendarias Ciudad de los Césares patagónica y de El Dorado, respectivamente, no encontrando allí más que unos descendientes degenerados y antropófagos de los conquistadores, cuya descripción supone una condenación simbólica de la colonización española y, sobre todo, de las sociedades criollas del presente a que había dado lugar.

La tendencia distópica de la arqueoficción del período interbélico no fue la única respuesta del género a las tensiones sociales y geopolíticas contemporáneas. Paralelamente, una novela inglesa de influencia incalculable, cuya magistral adaptación al cine por Frank Capra en 1937, con el mismo título, multiplicó la difusión de su asunto y consagró Shangri-La como ejemplo paradigmático de mundo perdido ${ }^{9}$, regresó a las raíces históricas de la arqueoficción ${ }^{10}$

${ }^{9}$ Por ejemplo, en una arqueoficción de tema americano que describe de manera mucho más positiva para el legado hispánico la ciudad colonial perdida como es El Valle del Olvido (1942), de Enrique Guzmán Prado (José Mallorquí), la protagonista, hija del patriarca español que gobierna con autoridad paternal(ista) la sociedad utópica de ese mundo perdido, en que conviven armónicamente indígenas y españoles con mentalidad del Siglo de Oro, lo describe como sigue: "Nuestro Valle tiene algo de Shangri-La [...]. No está en medio del Tíbet, pero sí en los Andes. La vida no transcurre en él en medio de una juventud casi eterna, pero todo el que ha llegado a él ha querido permanecer allí para siempre" (Guzmán Prado 1942: 31a). El referente debió de ser la célebre película norteamericana, porque la novela inglesa que le había servido de base no se traduciría en España hasta algo más tarde (Horizontes perdidos, versión de H. C. Granch, Barcelona, Molino, 1944).

${ }_{10}$ Tras episodios de mundos perdidos en el marco de narraciones pertenecientes a otros géneros, como la parte dedicada a El Dorado en Candide (1759), de Voltaire, entre los primeros ejemplos de arqueoficción se cuentan dos utopías francesas, a saber, Le Vallon aérien (1810), de Mosneron, en que un viajero aerostático descubre en un valle perdido de los Pirineos una aislada comunidad agrícola patriarcal y comunista y, sobre todo, Les Battuécas (1816), de Mme de Genlis. Las Batuecas son una comarca montañosa de la región salmantina en que, según esa escritora, algunos godos habrían encontrado refugio tras la invasión musulmana de la Península Ibérica y allí habrían vivido ignorados hasta su descubrimiento, tras lo cual habrían decidido mantenerse lejos del resto del mundo y conservar sus utópicas costumbres -"[i]ls vivent dans une égalité absolue, ignorent l'argent, l'art, les métaux précieux, la propriété privée et subsistent par la culture et l'élevage dans une parfaite simplicité de mœurs" (Trousson 1999: 179)-. Esta novela, que se tradujo tanto al español como al inglés, se había inspirado en una leyenda popularizada por una comedia muy anterior de Lope de Vega titulada Las Batuecas del duque de Alba (1638). Esta obra podría ser la primera arqueoficción europea (existe un precedente mucho más antiguo de mundo perdido utópico, escrito por el poeta chino Tao Yuanming hace unos quince siglos). Al menos, la estructura típica del género, en su modalidad procolonial más conocida, ya está presente en la 
al imaginar una tierra aislada con todos los atractivos de lo utópico y hasta de lo paradisíaco. Lost Horizon (1933), de James Hilton, sitúa en aquel valle ignoto del Himalaya una población feliz y de extraordinaria longevidad liderada por un lama, un misionero europeo pluricentenario, que obra por convertir tal lugar en el refugio de una cultura amenazada por la destrucción bélica mundial, que ya se presentía próxima. De esta manera, el aislamiento del mundo perdido dejaba de ser un obstáculo que había de superarse a fin incorporar la raza superviviente a la civilización occidental moderna y pasaba a garantizar la posibilidad de preservar la utopía del pasado en medio de los horrores de la Modernidad, esto es, como un museo vivo de una edad de oro perdida. Por desgracia, el hombre contemporáneo ya no parece digno de disfrutar inocentemente la utópica ciudad soñada: el diplomático británico que llega a la mítica Shangri-La ideada por Hilton no la ha alcanzado por su esfuerzo explorador, sino que es llevado a ella para que suceda al anciano lama. Sin embargo, ni siquiera parece entender lo que esa utopía significa, pues acaba marchándose $\mathrm{y}$, aunque la nostalgia del paraíso es ineludible $\mathrm{y}$, al final de la novela, lo vemos intentando por todos los medios regresar a la ciudad feliz entrevista, es dudoso que la pueda recuperar, de forma análoga a cómo el oficial francés de L'Atlantide, de Benoît, que había escapado milagrosamente a la fascinación de Antinéa, termina por volver a adentrarse en el desierto en busca del edén erótico ( $y$ efímero) de la reina de la Atlántida sahariana. Esta última novela, que carece de cualquier subtexto utópico, ya presenta un tipo de héroe vulnerable e incapaz de aprovechar lo que se le ha ofrecido sin esfuerzo por su parte, de manera que pudo influir, asimismo, en la transformación de los tópicos del género en cuanto a la caracterización del aventurero moral o psicológicamente defectuoso, antes de que Hilton introdujera la inversión fundamental de sus polos positivo y negativo. De esta manera, la ciudad occidental moderna, que se presentaba más o menos claramente como modelo a seguir en la arqueoficción imperial, se convierte en el tipo de sociedad de la que se huye, prefiriéndose así la ciudad perdida del pasado, donde se conservaría un modo de vida de una sencillez pastoral y pretecnológica.

Este fenómeno de utopización nostálgica de la arqueoficción, consagrada sobre todo por Hilton y Capra, cobró mayor protagonismo en torno a la Segunda Guerra Mundial. Aunque en la narrativa popular siguió explotándose el potencial de aventura que entrañaban los mundos perdidos, las matanzas perpetradas, el horror

comedia de Lope: los descendientes semisalvajes de los godos perviven en el cerrado valle de las Batuecas hasta su descubrimiento e incorporación a la civilización cristiana contemporánea, así como a los dominios feudales del noble explorador, el Duque de Alba. 
indescriptible del Holocausto, la amenaza constante de una técnica que, desde Hiroshima, ya era capaz de terminar con el género humano, y la crisis cultural coetánea de la Modernidad favorecieron seguramente una nueva valoración de la antítesis de la civilización moderna, esto es, de lo primitivo, lo que también se vio favorecido por una antropología ya muy alejada del social-darwinismo primario de sus comienzos. Esta nueva actitud y su consecuencia en la literatura es patente en Los pasos perdidos (1953), de Alejo Carpentier, un texto paradigmático del género en el período de la Guerra Fría. Esta obra maestra tiene un posible precedente peninsular en la novela que nos ocupa, Los que no descienden de Eva (1931), de Luis Antonio de Vega, quizá el autor colonial español más destacado, aunque esta calificación exigiría matices tras la lectura de esa novela, la cual resulta a menudo subrepticia y paradójicamente anticolonialista.

\section{Los pasos perdidos de Luis Antonio de Vega: Los que no descienden de Eva y el paraíso imposible}

Luis Antonio de Vega es recordado, de serlo, sobre todo por sus narraciones ambientadas en el Marruecos del protectorado español, en cuyas ciudades de Larache y Tetuán residió bastantes años. Pronto se prendó de aquel ambiente, hasta el punto de aprender las lenguas locales y de mantener estrechos tratos con la población autóctona, tal como se desprende del aire de observación genuina que rezuma su obra. Su cercanía a los naturales del país no se tradujo, sin embargo, en una solidaridad con sus anhelos de independencia, pues fue siempre un defensor de la labor de España en el protectorado y, asimismo, apoyó activamente la política colonial del franquismo, con el que se alineó desde el principio. Por ejemplo, durante la Guerra Civil de 1936, publicó en la prensa falangista relatos de propaganda como el curioso "El alfakih del pañuelo celeste" (1938), en que el protagonista desbarata una conspiración soviética encaminada a arruinar el orden colonial con la ayuda de un aparato futurista de proyección de imágenes a distancia, según el modelo de los futuros technothrillers, y con un planteamiento y desarrollo, salvadas las distancias, no muy diferente al adoptado por John Buchan en sus novelas de espionaje e intriga en defensa del imperio británico. Vega escribió, de hecho, numerosos relatos de este último tipo, cuyos títulos son elocuentes, como Mis amigos eran espías (1943) y Espías sobre el mapa de África (1943), obras en las que no falta un humor de tintes paródicos y hasta vanguardistas. Otras novelas suyas norteafricanas explotan más bien un costumbrismo exótico y pintoresco, heredero hasta cierto punto del orientalismo romántico, como ocurre en Amor entró en la judería (1944) o Los hijos del novio (1945). Sin embargo, este costumbrismo no es una prolongación tradicionalista, sino que está oportunamente actualizado mediante 
una técnica narrativa cercana al reportaje. Sin embargo, Vega suele añadir un elemento no muy común en este tipo de ficciones periodísticas, a saber, su preferencia por la narrativa en primera persona, sea por un prurito de dárselas de aventurero, sea para conferir a la fábula un carácter subjetivo que la alejara del reportaje para incidir en su dimensión humana, de vivencia tanto más verosímil por cuanto hasta las peripecias más extravagantes se convierten imaginativamente en plausibles gracias a su imbricación en una experiencia supuestamente personal. El narrador de costumbres no es un mero observador, sino que participa íntimamente en el mundo descrito y le transmite su sensibilidad propia. Como explica Carrasco González (2009: 224-225):

Luis Antonio de Vega crea un pequeño mundo de fantasía y de misterios que adereza la extraordinaria vida colonial, la mezcla de religiones y razas, el color de las ropas distintas, el sonido confuso de las diferentes lenguas. A veces parece un desarraigado que se encuentra bien en este mundo provisional. Suele ser él mismo el protagonista de los relatos $y$, con su nombre y apellidos, se ve trasladado al lugar de su sueño, a la aventura amorosa más imaginativa, al solar inexplorado de la raza perdida. Hay en sus novelas unas características comunes: enlazar con igual simpatía a moros y judíos, describir con igual entusiasmo sus barrios separados, deslumbrar las costumbres ancestrales y los ritos familiares 0 religiosos. Y hay una predilección latente por la mujer. El misterio de la desconocida encarna el ideal entrevisto, pero nunca alcanzado. Y, entre las mujeres, un regusto sin disimulo por las prostitutas cuyos barrios son el escenario habitual de muchos capítulos. $Y$ por las espías existentes 0 inexistentes que poblaban las colonias como pájaros de estación. Siempre en la indagación, tras la mujer-madre o, más aún, la mujer-amante, el ideal imposible simbolizado en profesiones inestables y desaconsejables.

Estas características se dan también en las "dos mejores novelas de Luis Antonio de Vega", en las que el autor "es el protagonista de dos extraordinarios relatos de aventuras y misterio, de fantasía pura, de humor irónico, de ternura, y de amor imposible como siempre" (228), según el mismo estudioso. En ellas, Vega se distancia algo del costumbrismo neorrealista típico de su obra para pergeñar espacios de fantasía en los que se plantea sobre todo el choque entre los sueños y una realidad conformada por siglos de tradición, mientras que lo colonial y su dimensión política se quedan en mero trasfondo de unos conflictos en gran medida independientes de la realidad coyuntural del protectorado. De hecho, estas dos novelas ni siquiera se desarrollan en este, sino en la Argelia francesa en el caso de Yo le di mis ojos (1952) y en un lugar ignoto del desierto en Los que no descienden de Eva (1941). De ambas, la 
publicada en fecha más tardía es la más convencional o, al menos, la que se aleja menos de la manera característica del autor. Su premisa argumental es claramente fabulosa: el protagonista dona sus ojos $y$, tras su muerte, estos son transplantados a una joven morabita, que vive desde entonces el conflicto entre su personalidad enteramente sometida a las costumbres de su pueblo y la presencia cada vez más invasora de la mentalidad moderna occidental y masculina del antiguo dueño de los ojos. No obstante, Vega presta atención sobre todo a los hábitos y creencias de la cerrada y rigorista sociedad de los bereberes ibadíes del valle argelino de Mzab, lo que rebaja considerablemente el alcance propiamente fantástico de la novela. En cambio, Los que no descienden de Eva reduce el realismo fotográfico al mínimo en favor de la invención de un mítico mundo perdido, mediante el cual Vega da rienda suelta a su vena especulativa y utópica, creando así una parábola de una coherencia y unidad estilística y de sentido que contrasta favorablemente con el desequilibrado abigarramiento de sus demás novelas, derivado de su gusto por la mera anécdota o el detalle pintoresco. En Los que no descienden de Eva, esa anécdota se supedita claramente a un fin. El tipismo de las primeras páginas no se explota como tal fuera de una ambientación exótica que contribuye, por el alejamiento de su espacio imaginario del conocido por la mayoría de los lectores hispanos, a prepararlos para suspender su incredulidad en el extraño universo del valle aislado del mundo a que Vega los transporta. Como señaló Melchor Fernández Almagro al aparecer la novela (1941), el libro no solo era importante por significar un ejemplo del género, no muy frecuente en la literatura española, de "la novela de viajes, de ambiente exótico, de aventuras", sino también por la dimensión más profunda añadida:

[S]egún vamos recorriendo, llevados de máximo interés, los capítulos de dicha novela, advertimos que la invitación al viaje que nos hace la Musa gentilísima de Luis Antonio de Vega es de más vuelo aún, de tentación más poderosa, puesto que Marruecos sirve en este caso de tránsito a un mundo fantástico y lírico, con lo que el atractivo color local que, sin mucho más, hubiera bastado a solazarnos, se resuelve en tonos y luces de más profunda motivación; luces y tonos de narración poemática, no exenta de otros elementos étnicos o sociológicos que enriquecen su contenido y que, trabajados con sumo arte, no pueden por menos de contribuir a la varia y penetrante seducción del conjunto. (Fernández Almagro 1941: 10)

A este atractivo estructural, por así decir, se suma para el crítico el acierto de la prosa de Vega, cuya variedad de registros justifica, en su opinión, la valoración del "mucho abolengo literario" de la curiosa aventura narrada, "cuyas peripecias se nos refieren en prosa animadísima, tocada de poesía, que a veces se completa y 
afina con la exploración psicológica y que en alguna ocasión se hace sátira e ironía". El juicio no puede ser, pues, más positivo. Sin embargo, la novela, que había ganado el primer premio "Miguel de Unamuno" de ediciones Patria, solo se ha reeditado dos veces (en 1941 y en 1956, sin apenas más cambios que la supresión del epígrafe coránico inicial). Tampoco ha suscitado prácticamente comentarios posteriores hasta el presente, quizá por la persistente falta de consideración de determinados géneros como la novela de aventuras o la ficción científica desde el (anti)franquismo, a diferencia del respeto mostrado hacia esas modalidades literarias por los mejores críticos de la primera mitad del siglo XX, Fernández Almagro incluido. Precisamente, Los que no descienden de Eva aúna aventuras e invención de un universo que resulta tan ajeno a la humanidad del mundo real que lo que destaca es su dimensión utópica e, indirectamente, fictocientífica en sentido lato ${ }^{11}$. Aunque Vega siga el esquema narrativo habitual de la arqueoficción clásica, en la que gran parte de la fábula consistía en la narración de las vicisitudes del aventurero hasta llegar al territorio escondido y la descripción de este quedaba relativamente en segundo plano respecto a la actuación del protagonista en aquel lugar, las aventuras contadas en Los que no descienden de Eva carecen voluntariamente de tensión. El explorador no corre peligro de muerte, resultando el viaje incluso relativamente fácil, sin obstáculos ni oponentes dignos de nota. Vega reduce así a su mínima expresión todo aquello que pudiese hacer sombra al aspecto puramente intelectual de su búsqueda, cuyo carácter eminentemente individual elimina también cualquier significado colonial directo de la empresa. No se trata de embarcarse en una expedición para apropiarse y civilizar un espacio virgen para el hombre blanco, sino de satisfacer la curiosidad de saber más y, en última instancia, de redimirse en cierto modo mediante tal conocimiento, en un contexto de colonización ya consumada.

${ }^{11}$ Según una definición ya clásica, aunque muy discutida, "SF is distinguished by the narrative dominance of a fictional novelty (novum, innovation) validated both by being continuous with a body of already existing cognitions and by being a 'mental experiment' based on cognitive logic" (Suvin 1978: 45). Sin embargo, Suvin afirma en el mismo estudio que su definición no se aplicaría a la mayor parte de las arqueoficciones, porque "as a historical genre, the lost-race tale uses instead [of novum] (and on the contrary) uncouth combinations of tribal, slave-owning, and feudal societies, usually with a beautiful princess and wicked high priest in trio with the virtuous white explorer-protagonist", en un ejercicio de "nostalgia of primitivism" (51). Sin embargo, esta nostalgia de lo primitivo es perfectamente compatible con la existencia de un "'mental experiment' based on cognitive logic" y con un planteamiento satírico e inconformista, tal como Vega demuestra, por ejemplo, en Los que no descienden de Eva, cuyo novum sería la existencia sobre la Tierra de un pueblo intrínsecamente libre de pecado, esto es, de la capacidad de hacer el mal. 
El inicio de Los que no descienden de Eva nos presenta una sociedad colonizada ciertamente exótica, pero ya estabilizada y sin verdadero peligro para el europeo. Este cuenta su historia en primera persona. "En el año 1930, en un diciembre disfrazado de abril" (Vega 1941: 9), declara haber oído por primera vez de la existencia de una tierra fabulosa Ilamada "Beld-el-Buhlali", esto es, "la tierra de los tontos" (16). Esta extraña denominación se debe a que los habitantes de esta tierra no procederían del mismo tronco que los demás seres humanos, ya que no descenderían de Eva y, por lo tanto, no habrían conocido ni el pecado ni sus consecuencias. Tontería equivale, pues, a inocencia paradisíaca. El narrador, espoleada su curiosidad, indaga y se entera de que los "buhlalis" o tontos se distinguen por tener los ojos de color violeta. Por casualidad, se tiene que hacer cargo de un bereber andrajoso y herido que tiene precisamente la mirada de ese color. Entre otras cosas para enterarse de más detalles, el europeo ayuda a sobrevivir al supuesto y poco locuaz buhlali. En agradecimiento, pide a su benefactor que compre un par de dromedarios, lo que da pie a Vega a escribir unas páginas en que pone en escena, con vívido aire de reportaje, el modo magrebí de regatear. El narrador y su misterioso guía se ponen luego en camino. El primero está intrigado, pero también teme una celada bereber, ya que no faltaban los precedentes de españoles secuestrados por los aguerridos cabileños. No obstante, la aventura solo se sugiere como posibilidad. Aunque se alude a diversos riesgos, el viaje no da pie a peripecias en que el europeo tenga que demostrar su valentía y arrestos de colonizador. Al contrario, va a remolque de su acompañante, que representa el enigma que desea dilucidar. La delgada intriga se articula primero en torno a las suposiciones del narrador y a sus ardides sucesivos para penetrar en el secreto. Llega hasta el extremo de fingir plegarias como si fuera un creyente del Islam para observar la reacción del nativo de los ojos violeta, pero solo queda claro que este tampoco es musulmán, si bien conduce al protagonista a un "morabo" o tumba de santón local para hacerle jurar que no revelaría a nacido alguno la ruta que lleva "a aquellos cuyos primeros padres fueron Adán y Batx" (93), al sitio "donde en los siglos de los siglos no ha puesto jamás sus pies ningún descendiente de Eva" (96). Al espesar el misterio, estas palabras orientan la atención hacia el destino del viaje, intensificando las expectativas, mientras que la narración del trayecto queda en un segundo plano.

El europeo y el buhlali alcanzan sin novedad una barrera de piedra, que marca el límite entre el mundo corriente y el fabuloso mundo perdido. Tras atravesar el roquedal por una hendidura tan angosta que tienen que arrastrarse durante horas en lo que parece una especie de nacimiento al revés y que constituye la mayor dificultad iniciática, acceden a "un valle bastante extenso, verde, 
jugoso, floreciente en el declinar del año" (120), un valle milagroso en esas latitudes y que la forma de embudo invertido de las montañas circundantes mantiene al abrigo de los exploradores de la naciente aviación. Los acogen allí algunos habitantes, todos hombres, con los ojos de color violeta, velludos y completamente en cueros. Poco después llega una mujer, que representa una feminidad física ideal tópica para muchos varones mediterráneos: es rubia y luce "esa blancura que suele tener la piel de las sajonas" (125), exactamente igual que las demás féminas del valle, todas ellas "rubias y finas", de cuerpos esbeltos y bien dibujados. En cambio, los varones son, tampoco sin excepción, "morenos y cubiertos de pelo" (138), como si respondieran fielmente a un arquetipo ancestral e ideal de sexos no solo diferentes, sino hasta opuestos en su apariencia, como para despejar cualquier ambigüedad. No obstante, conviene precisar que la marcada distinción física no tiene una dimensión cultural en Los que no descienden de Eva, puesto que su pueblo perdido paradisíaco se distingue de todas las sociedad humanas, incluidas las primitivas, por la inexistencia de los roles de género, los cuales se adscriben implícitamente, en consecuencia, a la civilización. A esta pertenecen, asimismo, las relaciones de poder, que el europeo, de forma muy verosímil, busca en la sociedad a la que ha llegado. Por eso cree erróneamente que Usoa, aquella primera mujer vista en el valle, es una especie de reina o princesa, de acuerdo con el cronotopo habitual en el género arqueoficticio. Por lo demás, es Usoa la que asume de manera espontánea la tarea de ir presentando al descendiente de Eva la tierra donde se encuentra, si bien con una parsimonia que contrasta con el tópico del guía entusiasta y apologista que enseña las maravillas de la ciudad utópica al boquiabierto visitante.

En el mundo perdido imaginado por Vega, el protagonista es acogido de forma tan distante que no sabe si considerarse prisionero o huésped de sus moradores, de manera que prosigue la explotación irónica de los tópicos del género, especialmente la exigencia de riesgos para impulsar la aventura, a lo que se suma una paranoia política que anuncia la de la Guerra Fría: al oírlos comunicarse entre sí en una especie de vascuence, cree incluso que se trata de compatriotas implicados en los oscuros tráficos y espionajes novelados por Vega en otros libros suyos. Solo más adelante dará crédito a la explicación de que ese idioma es un vestigio prebabélico, de acuerdo con la percepción tradicional de la antigüedad suma de todo lo euskaldún. Incluso buscará precedentes o semejanzas con las costumbres rurales vascas en ese mundo todavía incomprensible. El registro aventurero parece dejar paso entonces a otro más idílico, contaminado por las nostalgias ruralistas de la literatura costumbrista conservadora de la tierra de origen del narrador. Sin embargo, este nuevo intento de asimilación imaginaria del mundo descubierto para domeñar su extrañeza, también se deconstruye irónicamente, pues la 
tierra de los tontos tiene tan poco que ver con una vida campesina tradicional idealizada como con las modernas rivalidades políticas internacionales. Su primitivismo es tan pronunciado que desmiente cualquier parentesco con la esfera de la cultura.

No hay construcciones, sino solo cuevas en las que "todo el confort quedaba reducido a un montón de paja seca" (140) y el agua y los alimentos (una papilla) se presentan en concavidades de la roca. A esta simplicidad extrema se añade que la ciudad primitiva de los tontos parece carecer de cualquier tipo de organización social ${ }^{12}$. Aparte de la falta de construcciones, no se distinguen tampoco espacios de reunión. El lugar aparece solitario y no se ve trabajar a nadie, si bien el valle, no muy extenso, está dividido en parcelas, en cada una de las cuales fructifica una simiente distinta. Aquí y allá, corren algunos gallos y gallinas, como únicos animales domésticos. La vida económica, como la urbana, está reducida al mínimo. Los campos producen sin necesidad de cultivo, aunque hay quien cuide de ellos por el placer de la jardinería, mientras que el oro del río subterráneo les sirve para pagar la harina y la leche agria que constituyen la base de sus papillas. Al parecer, el viaje del buhlali herido era de aprovisionamiento para la pequeña tribu (doscientas cuarenta y cuatro personas), la cual conoce, pues, la existencia del resto del mundo e, incluso, mantiene una cierta relación simbiótica con él. En consecuencia, su aislamiento parece voluntario, como si el valle fuera un conservatorio-refugio de un modo de vida sencillo y pacífico, de un primitivismo idealizado, en lo que coincidiría con el descrito en una arqueoficción que puede considerarse un precedente de la de Vega.

Noëlle Roger había publicado en 1939, en tres números (434436) de la revista muy difundida La Petite Illustration, una novela titulada La Vallée perdue. Según la misma, en dicho valle situado en medio de los Alpes suizos y rodeado de montañas tan inaccesibles como la tierra de los tontos, pervivía una población neolítica celosa de su forma de vida. Aunque solo tuvieran vagas nociones de la civilización moderna, estaban al corriente de las masacres perpetradas en las guerras, sobre todo en la primera mundial, sin olvidar la Civil española a que Roger hace alusión en diversos pasajes de su relato. La llegada por aire de unos parisinos al valle desencadena un proceso que pone en peligro la supervivencia de la sociedad primitiva, pero el mundo perdido consigue permanecer

12 Desde este punto de vista, se trataría más bien de una heterotopía, según la definición de Vieira: "Heterotopian spaces are spaces that present an order which is completely different -even opposite- to that of real spaces" (2010: 18). Sin embargo, preferimos seguir utilizando el término común y más específico de utopía como lugar puramente imaginario en que prospera una sociedad connotada perfecta y, por lo tanto, inmutable, como la de los buhlalis. 
inviolado. El protagonista se resigna a perder a la joven que lo había ayudado a escapar a la ejecución ordenada por los sacerdotes del valle y que había decidido regresar a él a fin de alertar a sus compatriotas para que se ocultasen de la exploración aérea prevista tras conocerse su existencia. El primitivismo de la sociedad perdida es una elección $y$, a diferencia de las arqueoficciones anteriores, Roger da a entender que esa sociedad es mejor que la contemporánea, violenta y materialista. En la narración de Vega, las explicaciones lacónicas de Usoa van dibujando un mundo aún más primitivo que el suizo, pero también más sólido por fundarse en una humanidad esencialmente distinta. Mientras que en el valle perdido suizo existen tensiones y una ley consuetudinaria rigurosa, en que está prevista hasta la pena de muerte, entre los tontos resultan inconcebibles nociones como la guerra o la mentira. Tampoco hace falta la ley, porque están exentos de la falibilidad moral intrínseca en el ser humano, la cual se simboliza en la tradición cristiana mediante el concepto del pecado original.

Los buhlalis o descendientes de Batx habían salido del Paraíso bíblico o coránico, pero no habían sido expulsados de él. Batx, la primera esposa de Adán, no había probado la fruta del árbol del bien y del mal. Según el mito del origen contado por Usoa, la primera madre había huido de las asechanzas de Satán y dado a luz, ya fuera del Edén, a una pareja de niños, él moreno y ella rubia, que serían los progenitores de toda la raza perdida, cuyo número se mantenía constante: para no desbordar el valle y evitar mezclarse con los hijos de Eva y que les alcancen de ese modo las consecuencias del pecado original, solo nace un ser humano sin pecado tras morir otro, en ambos casos sin dolor alguno y coincidiendo el sexo del bebé con el de la persona que hubiera fallecido antes.

Como es fácil de imaginar, el narrador tiene dificultades para creer estas explicaciones de Usoa. La naturalidad con que lo tratan, sin extrañarse por su aspecto tan distinto al de los nativos del valle le hace considerar su vieja hipótesis de la conspiración internacional, sin caer en la cuenta de que la división nacional o racial les es tan extraña a los felices moradores sin pecado como la idea de recurrir a la violencia. La ciudad paradisíaca no conoce ni el pudor, ni la propiedad, ni el patriotismo gregario, ni la imposición de unas voluntades sobre otras -"¿Mandar? En sus criaturas no puede mandar más que Dios" (175)-. Por otra parte, puede creer que se trata de una tribu herética de curiosas creencias que se hubiera refugiado en el valle para escapar a la aculturación. Sin embargo, sus cábalas chocan con el hecho inverosímil en cualquier pueblo de que las mujeres puedan dar a luz sin dolor, de forma natural y sin ayuda. Este fenómeno tiene todos los visos de sobrenatural para un ser humano normal y es lo que acaba convenciéndolo en mayor medida de que los tontos son, en efecto, una especie aparte, 
espontáneamente pura y feliz. A esa particularidad de la falta de dolor se suma que los descendientes de Batx tienen una costilla más que los de Eva. Por desgracia, en el momento mismo en que el protagonista puede convencerse por fin de que los buhlalis son verdaderamente los descendientes sin tacha de Batx cerciorándose de que el esqueleto de Usoa tiene un número impar de costillas y de que, por lo tanto, se encuentra en una suerte de segundo paraíso tan libre de males como el primero, no puede escapar a las consecuencias del pecado original. El narrador, que se había enamorado de la bella Usoa, no resiste a la tentación de besarla al inclinarse a observar la particularidad anatómica que ella comparte con el resto de su pueblo. La consecuencia es su expulsión de la tierra de los tontos. Su acto era, en ese contexto, profundamente agresivo, no pudiendo siquiera alegar ignorancia, pues ya se le había avisado:

[J]amás de los jamases, los hijos de Batx se mezclaron con los hijos de Eva, porque así está escrito desde antes que el mundo fuera, y porque siempre debe haber hombres y mujeres limpios de todos pecado, limpios del pecado original. (208)

De esta manera, la libido masculina, que subyace al motivo del aventurero seductor en la arqueoficción al uso, pasa de ser el motor principal de una asertividad viril que lleva a la conquista de princesas y territorios a aparecer como un defecto fundamental, como la deficiencia antropológica más grave de la humanidad mayoritaria, incapaz en consecuencia de reencontrar el Edén abandonado. Aunque el narrador maquille hábilmente su falla en las páginas finales, en que rememora líricamente su amor imposible por Usoa, no deja de reconocer que el beso impuesto a la mujer procedía del "légamo turbio" de su subconciencia, esto es, de un deseo irrefrenable que, más allá de lo sexual, suponía una rebelión contra la existencia actual de un bien ausente en el resto del mundo, "porque no podía admitir que hubiera alguien a quien el pecado original no alcanzase" (212). Frente a su contrafigura de Antinéa, que representaba en L'Atlantide de Benoît otro ideal inalcanzable, aunque opuesto (la mujer devoradora de hombres), Usoa simboliza el deseo de pureza, de inocencia prístina que posibilitaría merecer, según el mito paradisíaco, la posesión de una tierra sin dolor ni trabajos, así como el disfrute de una sociedad humana naturalmente armoniosa, esto es, la ciudad de Dios perfecta en su primitivismo natural frente a la ciudad de los hombres de lo artificial, el pecado y la guerra. A este respecto, no parece casualidad que Usoa, tras rechazar estupefacta los desplazados cariños del varón, revele en primer lugar su conocimiento del estado bélico permanente del mundo exterior, así como de la agresión colonial: 
-Sé -dijo- que los hijos de Eva os odiáis unos a otros, que habéis dividido la tierra que es de Dios, y que ahora vuestro Bled está invadido por otros hombres, por hombres que han aprendido a volar. (215)

El europeo, que admite ser "de los invasores" (215) del Norte, refuta con una sola frase cualquier justificación de la empresa colonialista, al contestar a la pregunta de cuáles eran los males que los marroquíes les habían hecho a sus conquistadores europeos que a él, "estos hombres no me habían hecho nada" (216). Aunque aluda de un modo (voluntariamente) poco convincente a razones de política internacional, lo cierto es que Vega se sitúa, en una fecha tan temprana como 1941 entre los que subvierten, de hecho, la expansión europea que aparentan apoyar, de forma análoga a como su actitud sexista tradicional, perceptible en la división neta de los hijos de Batx en dos géneros de físico opuesto, se deconstruye mediante el cuestionamiento de la agresividad sexual del varón. Este se muestra incapaz de controlar unos impulsos primarios que se presentan como subconscientes y culturales a la vez y que se ponen en paralelo con la agresividad bélica. Nos encontramos, pues, ante una actitud curiosa en un escritor colonial y conservador, pero no hay que olvidar que el trasfondo predominante en Los que no descienden de Eva no es político, sino simbólico. La ciudad soñada en esta arqueoficción no es una utopía construida, que mire hacia un nuevo orden más justo en un futuro hipotético estrechamente relacionado con el estado del mundo real en el presente. A diferencia de Hilton, cuyo Shangri-La es un refugio de la cultura humanista que se pondrá al servicio de los hombres en un posible porvenir más pacífico, la tierra de los tontos remite claramente al mito del paraíso perdido y su descripción supedita, sin denegarlo, el comentario geopolítico al antropológico y moral. Según la novela, aunque exista el edén, solo pueden disfrutarlo los nacidos allí. El protagonista de Los que no descienden de Eva es el primero en visitar ese lugar y la experiencia no puede sino fracasar estrepitosamente. Aunque desee quedarse a vivir en la tierra de los tontos, sobre todo por Usoa, es esencialmente incapaz de hacerlo. A este respecto, el pecado original es sobre todo una metáfora de la incapacidad del hombre de entender y vivir de acuerdo con el bien absoluto, para lo cual haría falta otra clase de humanidad.

El paraíso en la tierra no solo es concebible, sino que ha estado siempre presente en la fantasía occidental, en su dimensión míticoreligiosa o en la utópica secularizada moderna que la ha sucedido, sin desprenderse de la base arquetípica del edén ${ }^{13}$. En los dos últimos

${ }^{13}$ Según Braga, "on peut dire que I'utopie est une pseudomorphose renaissante du Paradis terrestre chrétien. Entre les deux il y a simultanément une ligne et une 
siglos, se ha soñado con él imaginándolo en forma de pasado superviviente, como en las arqueoficciones, o de posibilidad en un más allá temporal o geográfico, como en las utopías supervivientes o en la ciencia ficción optimista. Frente a este sueño, Los que no descienden de Eva sugiere que un mundo en que no exista el dolor, ni el ansia de posesión, ni la agresividad, exige una especie que no esté sujeta a las pulsiones de la humana. Ni siquiera bastaría una raza distinta, perdida o no. Vega anula así la oposición tradicional entre el hombre civilizado y el exótico sin civilizar (al modo europeo), sea este el tópico buen salvaje, sea el demonio sediento de sangre de la aventura imperialista al uso. El primitivismo de los tontos no es signo de atraso ni de una idílica simplicidad fantaseada, sino de una perfección primigenia, intrínseca y tan inmutable como su número. Los descendientes de Batx no son seres humanos idealizados, sino que se presentan como una humanidad ajena, creada aparte. Su existencia se opone irreductiblemente a la evolución y el cambio conflictivo a que siempre está sometida la humanidad común. El mundo armonioso y estable, es decir, utópico, emana naturalmente del ser de los buhlalis, de forma análoga a como del ser de los hombres emana el mundo distópico de la ciudad humana. Esta es el fruto de un esfuerzo que remonta al simbólico pecado original, el cual es intrínseco y condiciona por igual cualquier sociedad, primitiva, actual o futurísticamente avanzada. De esta manera, Vega va mucho más lejos que Roger o que, posteriormente, el Carpentier de Los pasos perdidos. La aldea selvática de esta última novela parece ciertamente paradisíaca, pero no está libre de defectos y, sobre todo, existe como posibilidad real: si su protagonista hubiera podido encontrar de nuevo el brazo de río que lo había conducido la primera vez a la ciudad primitiva, nada impediría su reintegración en ella. En cambio, Los que no descienden de Eva nos sitúa en una utopía inalcanzable por definición y, por lo tanto, imposible de reproducir, por mucho que se anhele recuperar la inocencia de los inicios. Ni una varita mágica ni un modelo de ciudad ideal listo para su uso pueden salvar al ser humano. No hay vuelta atrás posible y solo queda seguir soñando, como hace el narrador en su casa de Tetuán tras su regreso al protectorado.

Esta conclusión es profundamente pesimista y distingue esta arqueoficción de muchas otras, marcando su originalidad también dentro del registro utópico, que supone en general el carácter

solution de continuité, une unité dans la rupture" (2010: 39). Y más adelante, parafraseando a Krishan Kumar, "[b]ien que les intentions, les moyens et l'aspect final de I'Utopie soient distincts des aspirations sotériologiques chrétiennes, il y a derrière le projet utopique une tension fantasmatique, une pression émotionnelle et imaginaire irradiant des visions du Paradis perdu et du Paradis recupéré" (40). 
alcanzable de la perfección paradisíaca ${ }^{14}$. Ni siquiera se presenta al infeliz expulsado cultivando resignado su jardín. De este modo, una narración convencional en apariencia, que transcurre con sencillez engañosa y en la que el reportaje exótico y los pensamientos del protagonista no sobrepasan una verosímil medianía, acaba convirtiéndose en una reflexión desengañada sobre el deseo utópico del paraíso en la Tierra, que sería imposible con esta humanidad. La civitas paradisíaca no es para los hombres, que no pueden ni deben acceder a ella. Su aislamiento es la única garantía de que los representantes supervivientes de la beatitud y perfección primeras perdidas puedan subsistir ante el avasallamiento aculturador de la civilización contemporánea. Consecuentemente, el protagonista cumple su juramento de no revelar la existencia de la tierra de los tontos. A diferencia del optimismo cultural de un Occidente seguro de sí mismo y de su buen derecho que permea la arqueoficción anterior, Los que no descienden de Eva es tan radicalmente escéptico respecto a la catadura moral de la humanidad en sí misma como frente a la supuesta superioridad de las sociedades organizadas actuales. Así se suma al cambio copernicano producido en este género en la alta Modernidad y se inscribe, tras Salaverría y Baroja, en la tradición española de una arqueoficción refractaria a las fáciles certidumbres de la civilización occidental.

Su lección no pasará desapercibida del todo en la literatura española. Por ejemplo, una novela de intriga y aventuras titulada Kurna, ciudad sellada (1962), de Jaime Mallas Casas, adopta un planteamiento similar al de Vega al narrar con agilidad la llegada de unos europeos a un valle sahariano ignoto en que pervive una sociedad de tipo egipcio antiguo, aunque evolucionada en un sentido democrático y pacifista, y la lucha, coronada por el éxito, del héroe por preservarla frente a los designios colonizadores de sus compañeros de expedición. Como en Los que no descienden de Eva, la Modernidad violenta y explotadora se contrapone programáticamente al utópico mundo perdido, un mundo que encarna, como la tierra de los tontos, la verdadera civilización, de índole moral, frente a la idea del progreso capitalista (y socialista) ${ }^{15}$.

14 "Le Paradis terrestre, le Millénium et I'Utopie sont des places idéales conçues pour I'homme immanent. Ils promettent aux individus exceptionnels, aux élus, une récompense dans ce monde-ci [...]. Ils sont fondés sur la supposition que l'autre monde se trouve dans l'immédiate continuité de notre monde, que les deux univers ne sont pas séparés par des barrières ontologiques qu'on ne pourrait pas franchir sans changer de condition anthropologique" (Braga 2010: 26).

${ }^{15}$ El héroe da la espalda a la civilización europea moderna y adopta la arcaica superviviente: "Mario, el hombre del siglo XX, vistió a usanza milenaria, dispuesto a dar la gran zambullida en una civilización que casi desconocía el progreso, pero en cuyo seno los hombres comportábanse como seres verdadera y singularmente civilizados" (Mallas Casas 1962: 244). 
La diferencia principal entre las dos narraciones es el aprovechamiento más hábil e imaginativo por Vega de la dimensión mítica de su asunto, además de su superior pulso narrativo y pericia estilística, que parecen justificar el elogioso juicio de Fernández Almagro sobre la obra, haciéndola merecedora seguramente de un lugar honroso, como aportación original, en la arqueoficción internacional, en su vertiente moderna y (ambiguamente) utópica.

\section{Bibliografía}

BRAGA, Corin (2010): "Du paradis à I'utopie", en Du paradis perdu à I'antiutopie aux XVI $I^{e}-X V I I I^{e}$ siècles, pp. 21-55. Paris: Garnier.

CARRASCO GONZÁLEZ, Antonio (2009): "Luis Antonio de Vega", en Historia de la novela colonial hispanoafricana, pp. 219-230. Madrid: Casa de África / Sial.

CLARESON, Thomas O. (1985): Some Kind of Paradise. The Emergence of American Science Fiction. Westport, CT.: Greenwood Press.

FERNÁNDEZ ALMAGRO, Melchor (1941): "Los que no descienden de Eva, por Luis Antonio de Vega". ABC 10/VIII, p. 10.

FOUCRIER, Chantal (1994): "Introduction", en Pierre Benoît, L'Atlantide, pp. 7-29. Paris: Le Livre de Poche.

GUILLAUD, Lauric (1993): L'Aventure mystérieuse de Poe à Merritt ou les orphelins de Gilgamesh. Liège: Éditions du CÉFAL.

- (2000): "Atlantide et totalitarismes", en L'Éternel Déluge. Un voyage dans les littératures atlantidiennes, pp. 103-131. Paris: e-dite.

GUZMÁN PRADO, E. [José Mallorquí] (1942): El Valle del Olvido. Barcelona: Molino.

KHOURI, Nadia (1983): "Lost Worlds and the Revenge of Realism". Science Fiction Studies, vol. 10, núm. 2, pp. 170-190.

MALLAS CASAS, Jaime (1962): Kurna, ciudad sellada. Barcelona: Mateu.

RIEDER, John (2008): Colonialism and the Emergence of Science Fiction. Middletown, CT: Wesleyan University Press.

STREET, Brian V. (1975): The Savage in Literature: Representations of 'Primitive' Society in English Fiction 1858-1920. London / Boston: Routledge \& Kegan Paul.

SUVIN, Darko (1978): "On What Is and Is Not an SF Narration; With a List of 101 Victorian Books That Should Be Excluded From SF Bibliographies". Science Fiction Studies, vol. 5, núm. 1, pp. 45-57.

TROUSSON, Raymond (1999): Voyages aux pays de nulle part. Histoire littéraire de la pensée utopique. Bruxelles: Éditions de l'Université de Bruxelles.

VEGA, Luis Antonio de (1941): Los que no descienden de Eva. Madrid / Barcelona: Patria.

VIEIRA, Fátima (2010): "The Concept of Utopia", en Gregory Claeys, The Cambridge Companion to Utopian Literature, pp. 3-27. Cambridge: Cambridge University Press. 